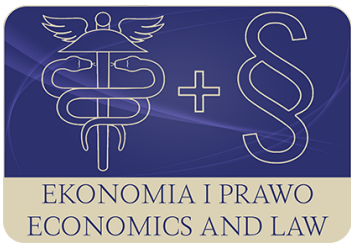

EKONOMIA I PRAWO. ECONOMICS AND LAW

Volume 15, Issue 4, December 2016

p-ISSN 1898-2255, e-ISSN 2392-1625

www.economicsandlaw.pl

EKONOMIA I PRAWO

ORIGINAL ARTICLE

received 03.02.2016; revised 15.07.2016; accepted 31.12.2016

Citation: Czetwertyński, S. (2016). Non-market information goods circulation and the copying culture in the Internet era. Ekonomia i Prawo. Ecomomics and Law, 15(4): 455-468. doi:10.12775/EiP.2016.030.

\title{
Non-market information goods circulation and the copying culture in the Internet era
}

\author{
SEAWOMIR CZETWERTYŃSKI \\ Wrocław University of Economics, Faculty of Economic Sciences, Department of Microeconomics \\ and Institutional Economics, ul. Komandorska 118-120, 53-345 Wrocław, Poland \\ $\nabla$ slawomir.czetwertynski@ue.wroc.pl
}

\begin{abstract}
Motivation: This paper deals with a relation between a phenomenon called a 'copying culture' and situation of information goods markets. Subject-matter was limited to phenomena taking place in the Internet and market \& non-market exchange taking place via the Internet.

Results: The copying culture is a significant social aspect which is reflected by activity of, among others, Internet users. Range of the phenomenon in question makes it cannot be ignored, especially, in context of economic efficiency that is profits from copyrights to works in form of information goods. The paper demonstrates a hypothesis that unauthorized copying via the Internet is a result of high level social consent to do so. The hypothesis in question results from observance of range of non-market information goods circulation, which is linked with impact of the copying culture.

Aim: Goal of the paper is provision of evidences justifying the hypothesis by means of analysis of retrospective practice of information goods copying as well as case studies dealing with contemporary examples of their non-market circulation.
\end{abstract}

Keywords: copying culture; copyrights; information goods markets JEL: Al4; K11

\section{Introduction}

Phenomenon of mass copying of digital intellectual property has become a sign of our times. Digitalization and networking of a society enables free flow 
of information goods. Copying of books and re-recording of cassettes has been replaced by copying of high quality files via the Internet. Range of the phenomenon makes it is not something which can be ignored. Acc. to surveys conducted by Joe Karaganis and Lennart Renkem (2013, p. 5) nearly half of inhabitants of the USA and Germany have copied materials such as music, movies or tv shows, protected by copyrights, in an unauthorized manner. Holders of copyrights have no effective tools or measures to counteract this phenomenon. Fight against Internet piracy or generally, media piracy seems to be tilt at windmills. Moreover, it is not a fight against a world of organized crime but with average inhabitants, who pay taxes and (generally) meet traffic road regulations.

Problem of violation of copyrights regards most of social groups operating in the Internet. These are neither marginalized persons nor persons of low income, whose acts could result from their economic activity. Moreover, practice of re-production of somebody else's intellectual property is trivialized in most cases. It is not as controversial as a theft, economic offenses or overconsumption of drugs. Generally, among members of a society copying is accepted even if it not permitted or it is just illegal. It is enough to visit the YouTube to notice that great number of works comprises materials copied without a consent. Numerous files with documentary movies, feature movies or TV shows are published openly by the users. In turn, holders of the copyrights react to such publication in an undecided way.

The YouTube is a good example that mass copying takes place openly even if this action has not been authorized. Another, also really good example is The Pirate Bay (TPB). Generally, it is files browser operating in the framework of a BitTotorrent system. Using it, in 2013 more than 200 million Internet users exchanged unauthorized information goods monthly (Price, 2013, p. 19). Controversies regarding the TPB are significant since a lot of attempts have been made to liquidate it, however, they've failed. This is the biggest repository of data on unauthorized copies available for everybody. Using it one may download the latest Hollywood productions or payable serials just emitted on TV. Moreover, content of the website is a result of work of the Internet users themselves, similarly like in case of YouTube.

Author of this paper attempts to grasp essence of this social \& cultural phenomenon in the context of economy. It is highly probable that such practices violate interest of holders of the copyrights and they hamper trust in copyrights. As works can be acquired in unauthorized way such a remuneration is not transmitted to those, who should get it. It seems it would not be accepted by society similarly to theft. However, giving consideration to the range of the phenomenon one can hypothesize that unauthorized copying via Internet is characterized by a high level of social acceptance. Goal of the paper is verification of the hypothesis in question. Moreover, the paper is a draft of concept of the copying culture. The term in question originates from a survey report by Karaganis and Renkem (2013), however, subject-matter of this paper is to consider it from the very beginning (retroactively). To prove the thesis a deduction method was 
applied. It was found true that the copying culture, similarly to a broadly defined culture, must have formed in a progress of social interactions in a certain period. This is why the author based his efforts on retrospective analysis of information goods and contemporary practices.

\section{The methodology of research}

In this paper a deductive approach was applied. By means of the afore-mentioned method the author made efforts to prove hypothesis advanced at the preface of the paper. Considerations were conducted in two main fields. The first one concerns emerging of informal norms and samples of information goods copying. A retrospective analysis was carried out. It enabled to advance general rules governing attitudes and social actions in the further part of the paper. In the context of the second field, general information based on retrospective approach was referred to the temporary society having communication tools not available at previous stages of social development. Examined examples and statistics related with an informal trade of information goods aim to make some generalizations adequate to a present social order and having economic consequences arising from a society's approach to the formal copyrights.

\section{Genesis of the copying culture term}

The term — copying culture — was used by Karaganis and Renkem (2013), who based definition of the term on attributes of the culture that is: copying, sharing and download of music, movies, TV shows (serials) and other digital media. It is not an accurate definition since extent and its ostensive character makes it is far away from being universal. A 'quite' assumption is that the actions are informal. In a report regarding social circulation of content Mirosław Filiciak et al. (2012, p. 21), refer to informal content circuit which, similarly to informal economy, stays beyond affection of national or scientific regulations and it is not taxed. Similarly, the copying culture means actions, which are informal practices.

This term has still been imprecise, but generally it is clear - it comes about unofficial, even illegal circulation. Nevertheless, there emerges an aspect of criminal actions emerges since illegal circulation can be identified with a black market. However, Karaganisan and Renkeman (2013, p. 11), Filiciak et al. (2012, p. 4), do not focus on this issue. To make the copying culture term clear, a definition followed by the author is that it is system of behaviors meaning non-market re-production of information goods, taking place acc. to patterns common for a particular society, created and purchased during a process of social interactions. The second part of the afore-mentioned definition originates from Antonina Kłoskowska (2011, p. 40), who points out that a culture is 'relatively integrated entirety comprising behaviors of people taking place acc. to patterns common for a society, created and adopted in a progress of interactions, inducing effects of such behaviors'. The proposed definition decreases ex- 
tent of actions but the part, which refers to the patterns, is generally the same. It is totally conscious action since it is supposed to prove that the copying culture does not originate from nowhere but it has formed up in a way appropriate for other systems of human behaviors. It is not also a contemporary creation since its present form has been affected by patterns originating from previous periods. This observance is very significant in the context of hypothesis herein on considerable social acceptance for such type of practices.

The definition in question is universal. For needs of this paper it has to be narrowed down since the author considers role of the copying culture exclusively in relation to unauthorized copying which means breach of copyrights. Hence, there were omitted issues of non-market copying, which is not limited by means of copyrights, e.g. such expressed in a copyleft concept (Brol \& Czetwertyński, 2013, pp. 137-150). It should also be reminded that it concerns actions using both, modern media (mainly Internet) and traditional ones. Hence, there was used information goods term which is information intended to satisfy human needs irrespective of carrier they are recorded on. Consequently, designatums of the definition in question is copying of a book of a colleague, but also downloading of a movie from an unauthorized source via Internet. The fact that copying takes place out of the official market means also exemption of a black market. Therefore, extent of the term does not comprise actions related directly to gaining tangible profits from unauthorized (and in most of legal systems also illegal) copying of information goods. It is very important because of separation of the copying culture from criminal acts, which belong to other group of human activity. One should also take into accounts that in the frameworks of the copying culture there takes place duplication instead of transfer (borrowing) of information goods. It is a meaningful difference since it makes there occur new copies which can be used simultaneously.

Let's get back to the second part of the definition related to occurrence of a pattern. The copying culture must have its source embedded in previous norms. They (norms) were, however, subject to other circumstances and their function was different. To find a direction of this re-construction one could rely on Paul Levinson's remarks regarding conversion of media and consequences of the conversion. They shall be supported by scientific output provided by: Stanley M. Besen, Besen and Sheila Nataraj Kirby, William R. Johnson and Stan J. Liebowitz. As an effect of the discourse it shall be proved that patterns of behaviors in the framework of the copying culture originate from previous, approved patterns belonging to a broadly defined culture. This fact, in turn, has an impact on present approach of the society to the practice of copying of information goods out of the market circuit.

Levinson (2006, p. 49), when considering impact of media on social development makes a remark on a break of monopoly of the church on transfer of knowledge which took place together with implementation of a printing press in the Europe. In the context in question it means mass copying of writing materials, which has been so crucial to preserve the culture (output) (McLu- 
han, 2004, p. 135). Before Gutenberg invented the press (and before it was enhanced) process copying of books had been taking place in medieval scriptoriums. Arduous copying of books by monks was replaced, at first - by manufacture production and then, mass production (Dahl, 1958, pp. 82-157). Papers stopped being deficit goods.

Implementation of the printing press is also a caesura of definition of copyrights (institution). Levinson (2010, p. 128), mentions that originally authors and printing houses were supposed to be controlled. In practice it meant a limited number of available copies and the number was decided by monarchs. Genesis of copyrights is related to duplication of copies as it took place in the big time of scriptoriums. Issue of who was entitled to a copy, to gain profits and to use fragments to produce new items was not subject of consideration. A medieval scriptor was interested in accuracy of a copy (Levinson, 1999, p. 121). Scriptor hadn't to consider a damage, which could potentially be caused, by copying of a book since mainly the Bible and ancient times authors' works were duplicated. As late as at the beginning of the seventeenth century, by virtue of The Statute of Anne, English legislator granted a legal protection to authors. Before the time in question it is hard to consider copyrights in the meaning we know. Hence, beginning of a pattern of information goods copying dated on Middle-Age, is of knowledge dissemination character (what knowledge and to what extent is another issue). Gutenberg press accelerated this process and broke monopoly of the Catholic Church. Nevertheless, words in writing were still used mainly to disseminate certain ideas - Reformation of Martin Luther was the best example of it (Levinson, 2006, pp. 54-57). Copying of information goods is, in the period in question, carrier of a rebellion, a revolution to a some extent, as well as control and forming up of authority order.

Next technological revolutions enhanced copying machine and added some other forms of information goods, such as photo recording, sound recording and movies. At the turn of nineteenth and twentieth century, copying of cinematographic materials was reserved to professional laboratories such as studio of Thomas A. Edison. It limited the issues of non-market circulation to a small chain of particular entities which were able to copy and display works of contemporary cinematography. It could seem that at such a small number of players on the market the non-market circulation should not exist. It should be recalled that the intellectual property right already existed but it was not as restrictive as it is today. Despite it, Edison copied and distributed movies of Georges Méliès - French pioneer of cinematography, in his chain of cinemas without the George's consent (Solomon, 2011, p. 2). From the other hand, he strictly enforced execution of his own patents which caused 'independent producers' associated at the Western Shore (Hollywood), far away from Edison's influences. Beginnings of the cinema were an interesting battle in the field of rights to copy. It is surprising that the branch was open and popular and simultaneously, it was source of conflicts based on law intended to protect it. 
The last civilization development stage interesting for us and having an impact on contemporary copying culture is period of popularization of copying machines intended for an average user. Cassette recorder, video recorder and photocopier are the most known examples of analogue era copying machines. Originally, these were rare devices poorly available and relatively expensive. Hence, phenomenon of non-market copying of information goods could not be common. As a marginal one it was not controlled. It can be explained in a category of economic account. Legal beneficiaries of incomes originating from sale of information goods are manufactures. Hence, if resources spent on finding consumers, who copy information goods, and on enforcement of copyrights is more expensive than profits which could be generated strictly on the market, marginalization of the phenomenon in question is rational. Nevertheless, commonness of this practice in 50's of twentieth century was beginning of serious differences between interests of publishing houses and consumers at the end of the twentieth century.

In the middle of 80's the impact of dissemination of copying machines in a society was subject of considerations by Besen (1984), as well as Besen and Kirby (1987). They paid attention to the fact that information goods in a non-market circulation are not ideal substitutes of goods existing in the market. This thesis was referred to the efficiency of system of royalties. The worse a substitute is the more efficient system of royalties. Phenomenon of reduction of royalties in relation to number of copies among consumers was correlated by them with increase in so called private copying, which is practice of share of information goods within small social groups characterized by direct relations. Example of this is recording of cassettes. It is also an activity having its social \& cultural aspect. Personal compilation of works (music) can be a sign of social commitment - picture of an individual or knowledge of particular music genre. Such a practice is of non-authorized character but for sure it has not been (neither in 80's, nor now) deemed an illegal action. Copying of a paper by a student is not deemed an illegal action. Moreover, it shall be found a symptom of positively rated education process. This issue was subject of interest of Liebowitz (1985, p. 956), who focused on copying in the context of sector of scientific magazines. He found that copying has no a substantial impact on the sector (financial results of publishers). Copies are made by a particular type of people and organizations, who buy materials in order to copy them later. Levinson (2010, pp. 128-129) invokes a 'fair use' term of (in Polish this term is permissible use) (Act of 4 February 1994). Idea is, irrespective of a legal system, to counteract monopolization of knowledge. Levinson says it is a custom law respected by courts even if it has not been formalized. The most frequently one may copy works for his/her own use, for non-commercial goals, among related people, in order to disseminate general knowledge etc. Extent may vary but usually it is connected with low economic meaning or with a scientific activity. In works (papers) focused on issue of the fair use there is also mentioned a decision of the supreme court which 
stated that making a copy of video cassette, intended to be displayed later, can be classified this way (Klein et al., 2002, p. 205).

This short characteristics of copying practice shows that in the previous stages of development of civilization, copying - out formal market circuit, was something natural, marginalized or classified as a business practice. There also occur trains regarding shape of social approaches, promoted by persons, who are supposed to be protected by copyrights. A way towards the copying culture is dual. One of its 'lanes' leads through patterns promoting copying (practice) or marginalizing this practice and trying to reduce it to the private copying. On this ,lane' one may find examples of breach of copyrights by publishers, which make other to think no formal norms need to be met. The second ,lane' is development of copying technology and communication. Technological growth clearly moved non-market copying practices into a fully new level. Shape of the copying culture patterns have surely been also affected by economic issues, not only by previous patters of behaviors. Nevertheless, the thesis forwarded at the preface limits area of considerations to social practices and informal norms. The copying culture is also an inevitable consequence of history of dissemination of information goods arising from human needs.

\section{The copying culture in modern society}

If copying culture is a resultant of previous social processes, why is it so controversial in the twenty first century? Such practices took place earlier and they were not a central problem for publishers. The real question is a question on range of the issue at subsequent stages of Western civilization. Johnson (1985, p. 172), in 80's, paid attention that the private copying can be a source of social loses in a long period. Sense of such prediction proves success of Internet as a world information (information goods) exchange media among individuals. It should be also emphasized that digitalization made there have disappeared differences between an original and a copy. This is a characteristic feature of digital information goods. Compared to analogous copies, which could not be copied constantly, digital copies are copied in a perfect way. If an original is an object of particular properties then a copy is identical. In times of the analogous technology it was not possible since recording was constant and not steplike as in case of the digital technology. Copied cassette is different from an original while CD-ROM is the same - apart from the carrier itself which is not an essence of information goods.

Digitalization made a decrease of marginal costs which, at the same time, is source of profits for manufactures and their risk meaning common unauthorized copying. Unauthorized copies can be as cheap as the authorized ones. If a digital information product comprises its essence which is abstract information, and a carrier, the latter is a superior source of marginal costs. Digital technology is also applied to decrease an area which is necessary to place data physically. Carriers have become minimal which resulted in lower prices. This 
law is called usually Moore's law and it concerns a stochastic relation between increase of technological capabilities and a price of sub-assemblies (Moore, 1965, pp. 114-117). It is applied, among others, in relation to computational power, size of RAM memory and capacity of hard disks. It shows, very accurately, that capabilities of sub-assemblies get double at regular intervals.

The second aspect promoting non-market circulation of digital information goods is spread and increase of Internet transfer capabilities. Average consumers have had previously unavailable possibility to send and receive mass files. Dynamics of increase of data transfer in the last decade is amazing. During approx. one decade, acc. do data of Cisco Systems Inc. (2015, p. 4) developed in the framework of Cisco Visual Networking Index (CVNI), Internet traffic went up from 100 GB daily as of 1992 to 29 GB per second in 2013. Statistics show data exchange capability Internet users have now. It significantly affects extent of the private copying. People, who exchange files, are no longer relatives. However, it can be contrasted to exchange of play lists - described by Chris Anderson, taking place between friends - e.g. students of a particular class (Andreson, 2008, p. 249). It is important that we know person who we copy from. It is nearly improbable we copy music files from a person we met in a street. In a real world the private copying requires existence of a relation. It does not have to be close but it is necessary to start copying. In case of the Internet, character of the private copying is reversed - anonymous. However, it does not come about real anonymity but about no close relations between persons, who copy files.

David Price (2013, pp. 4-6), enumerates three basic sources of non-authorized (including illegal) information goods. These are BitTorrent, stream video and cyber-lockers. Each of the above sources is, in fact, method of sending and reception of data. BitTorrent system is based on P2P that is peer-to-peer protocol. It means sources are co-shared among its users. This mechanism omits classic form of data flow which is client/server. It works on the basis of something (in exchange) for something. In order to download information goods one needs to make them available for others (Kuruse \& Ross, 2010, pp. 194-196). Co-shred files are kept in particular computers of individual users and by means of BitTorrent protocol they are co-shared. A condition is that those, who download and upload (files), must be constantly connected with the Internet. In case there are many users, transfer takes place very efficiently. If there are a few users only, absence of one of them can cause others cannot download a file since the missing person has the missing element.

A system, which is resistant to this defect, is cyber-lockers that is hosting of files or, in other worlds, on-line service which enables co-sharing of files (even large ones) (Mullin, 2011). In its essence it is similar to a contemporary concept of a cloud, which means storage of private data at external servers which can be accessed online. The most popular cyber-boxes websites are RapidShare, Hotfile and Megaupload, and in Poland - Chomikuj.pl. 
Stream video belongs to a category of stream multimedia transmission which is sending of compressed audio and video files via Internet websites (Kuruse \& Ross, 2010, pp. 690-691). Stream video can be connected with files hosting services (for e.g. cyber lockers) or individual site, such as YouTube or Dailymotion or Polish Wrzuta.pl. They can also be iMovies4you, Serialeonline.pl or Any-Files. They are less popular ones but they have the same meaning, mainly because of legal controversies.

Surveys of use of these distribution channels are conducted in the context of breach of copyrights or the Internet traffic. Serious analytical problem is related with the last source, since in the framework of it there takes place also market traffic and distribution of materials in line with copyleft (license) regulations (Brol \& Czetwertyński, 2013, pp. 143-145). In turn, meaning of sites promoting cyber lockers have been gradually dropping down (Price, 2013, p. 8). To the large extent it is related to legal nature problems. From four of afore-mentioned ones just Chomikuj.pl still exists. RapidShare (2015) withdraws from the Internet at the end of first quarter 2015.

It is estimated that total unauthorized transfer of information goods equals approx. 23.8\% of total Internet traffic (surveys took place in Northern America, Europe, Asia \& Pacific). Generally, it takes place from afore-mentioned sources (Price, 2013, p. 3). Analyzing data provided by Sandvine Inc. (2014; 2015), demonstrated in table 1, regarding sites generating the largest Internet traffic, one can observe clear repeatability. Irrespective of a region, YouTube, BitTorrent and HTTP (Internet websites) came first. An exception is Netflix site which provides the video on demand (VOD) service. It is very popular service in United States and - which should be emphasized, payable, that is it constitutes market trade with information goods. Services are much less available in Europe and hardly available in Asia (Richter, 2014), Where Netflix becomes a dominating source of information goods belonging to the category of home entertainment, share of BitTorrent in the Internet traffic drops down. Analytics of Sandvine Inc. (2012, p. 32) link a decrease of popularity of the BitTorrent in the North America and growing popularity of the Netflix. In Asia and Australia \& Oceania, the Netflix is unavailable and the BitTorrent has been growing up quickly.

The largest problem from point of view of market trade with information goods, is the BitTorrent network in the framework of which there takes place non-market circulation only. Via the network in question there takes place transfer of popular works such as movies and TV serials as well as music. Films have $33.4 \%$ share in traffic of data in the BitTorrent network, TV serials 15.3\% and music $7.6 \%$. Great share - 30.3\% has a porn content which, because of specificity, is not classified as movies (Price, 2013, p. 29). Via this channel the private copying takes place at global scale. To demonstrate that this phenomenon cannot be ignored, one can analyze e.g. Oscar awards 2015 nominees. In the best movie category there were nominated 'Birdman', 'Sniper', 'Boyhood', 'Grand Budapest Hotel', 'The Imitation Game', 'Selma', 'The Theory 
of Everything', 'Whiplash'. In the BitTorrent network, by the day of 87th Oscar Gala all of them were available. What is crucial, in official trade just two of them were available. In the table 2 there are listed nominated titles along with data of the world premiere and publication dates in the BitTorrent network. There is also provided an original source where a first upload into the BitTorrent network was carried out from.

Analysis of the table 2 shows an interesting feature. More of the titles were put into unofficial circulation more or less at the same time and their source were so called promotional copies. These are copies provided to persons related to the branch, e.g. critics of the Movies Academy which awards the Oscars. Colloquially, we face a leak. Obviously there is a suspicion that some of them could have been stolen but those, who know the environment, state that usually a copy originates from a critic or somebody related to him/her (TorrentFreak, 2015). Among demonstrated movies there are not movies nominated to other categories, such as: 'The Hobbit: The Battle of the Five Armies', 'Big Hero 6', 'Into the Woods', which were also uploaded to BitTorrent from promotional copies.

A little bit different example of non-market circulation is TV serials which are also very popular. Mainly it comes about super-productions such as Game of Thrones, episodes of which break records of non-market copying. Contrary to movies, unauthorized copies of which can occur before their premiers on Blue-Ray and DVD, episodes of serials appear in BitTorrent network just after their premiere. They are downloaded by viewers from authorized sources and then uploaded to the network. Main problem is in this case a global nature of non-market circulation. Market circulation requires observance of copyrights and hence, an episode cannot be displayed in every country at the same time. Non-market circulation is free from legal limits. Such a situation took place in case of display of 'Game of Thrones' in Northern America and Australia. Week of delay for Australia inhabitants caused that most of them carried out private copying from American spectators. Statistics of unauthorized circulation of episodes of the serial are so significant that they were commented by managers of the studio, which produces the episodes. In 2014 a final episode of the fourth season had nearly 7 non-market copies breaking its own record from previous year by nearly 1 million (TorrentFreak, 2013; 2014). In a comment regarding this tendency, Jeff Bewkes, CEO of the Time Warner, which the $\mathrm{HBO}$ (producer of the serial) belongs to said that 'high rate of copying of the Game of Thrones is better ennoblement than Emmy prize' (Tassi, 2014). This specific 'brave face on things' noticed in the world of media is a great evidence supporting the principle included in the thesis.

\section{Findings and results}

A copying culture is a consequence of norms and social behavior samples shaped long before the Internet. Their present form was significantly influenced by 
practices applied in a period, when information goods market did not exist yet. Historical analysis proves clearly that unauthorized copying has been socially accepted and a limiting factor was mostly technological barriers. Along with popularization of the copying technology there have grown up scale of information goods informal trade and simultaneously, the publishing and entertainment industries. As an effect there has occurred a conflict between interest of copyrights holders and a society influenced by the copying culture.

Rate of information goods exchange among Internet users proves a weight and a power of the copying culture which negatively affects observance of copyrights, in particular, in their proprietary context. The problem in question, marginal one at the beginning, has become a global one. One should emphasize that informal institutions, hence, the copying culture in this case, are very durable. It is indicated by a commonness of copying of information goods and relatively low efficiency of counteractions. As an effect, copyrights holders, in particular large movie factories and TV stations, try not to fight the copy culture but not to encourage copying beyond the market. This goal makes they adjust distribution channels to requirements of a contemporary society and at the same time, they try to get high rate of receivers, which is achieved by a relevant price policy. Consequently, non-market trade is losing its arguments since society members interested in information goods have unlimited access to them.

\section{Conclusion}

Copying culture is an unavoidable consequence of patterns and practices arising from previous periods. From a marginalized phenomenon and private copying it grew up to extent of a global problem which significantly affects both, social and economic order. Behaviors arising from the copying culture, which is natural consequence of patters and practices arising from period before the Internet revolution, are considered by a society to be relatively harmless. It is evidenced by commonness of use of the Internet for private copying to the previously unknown extent. Attention should be also paid to the impact of the holders of copyrights or entities, which, because of their role in the economy, must support the institution (of copyrights). And so, Chris Anderson noticed that by 2007 number of iPods in the market in relation to music works sold in iTunes, necessary to keep authorized music only on the devices would be just 25 items in every market (Andreson, 2008, p. 249.). In fact, apart from authorized copies, mainly unauthorized copies were stored in the memory of early iPods. Apple Inc. did not restrict this possibility in its first products in order to increase attractiveness of its equipment in eyes of users. Copying of files among users was a motivating factor to purchase the appliance. One could say that unauthorized copying was a part of business model. After some time there were implemented active operations (technological limits) intended to counteract this practice, which was related to growing position of the music store of the manufacturer. However, a habit of user stayed in place which is reflected by a large number 
of Internet guidelines on how to overcome protective measures. It should be mentioned that other manufacturers, among others, Samsung and LG do not apply any limits.

Other examples, described previously, are related to conviction of the society that the persons interested do not treat non-market practice of information goods copying seriously. Leaks of promotional copies and position of the CEO of the Time Warner makes a support for social acceptance of this sort of behaviors. However, these days the range of the phenomenon is too large to marginalize it. However, it is difficult to support a representation on alleged ruining of studios. Those, especially big ones, produce more and more expensive films which proves good condition of the entertainment sector and this situation makes a direct hazard regarding profitability of particular proposals.

In this paper the author did not use 'Internet piracy' term and did not consider legality issues since interest center of the considerations herein were not profit-related actions. The text is focused on issue of mass private copying in the context of co-distribution of information goods constituting substitute of market circulation. There is significant circumstance that existence of adjusted authorized source will eliminate mass of copying in a natural way. A conclusion can be drawn on the grounds of decrease of the meaning of BiTtorrent in regions, where Netflix operate. Hence, the copying culture will shrink to marginalizable range as it took place in previous periods.

\section{References}

Andreson, C. (2008). Dtugi ogon. Ekonomia przysztości - każdy konsument ma glos. Poznań:, Media Rodzina.

Besen, S.M. (1984). Private Copying, Reproduction Costs, and the Supply of Intellectual Property. Santa Monica: The Rand Corporation.

Besen, S.M., \& Kirby, N.S. (1987). Private Copying, Appropriability, and Optimal Copying Royalties. Santa Monica: The Rand Corporation.

Brol, M., \& Czetwertyński, S. (2013). Koncepcja copyleft w procesie wytwarzania dóbr partnerskich. Ekonomia, 2(23).

Cisco Systems Inc. (2015). The Zettabyte Era - Trends and Analysis, Visual Networking Index (VNI). Retrieved 15.12.2015 from http:/ / www.cisco.com.

Dahl, S. (1958). History of the Book. New York: The Scarecrow Press.

Filiciak, M., Hofmokl, J., \& Tarkowski, A. (2012). Obiegi kultury. Spoteczna cyrkulacja treści. Raport z badań. Warszawa: Centrum Cyfrowe Projekt.

Johnson, W.R. (1985). The economics of copying, Journal of Political Economy, 93(1).

Karaganis, J., \& Renkema L. (2013). Copy Culture in the US and Germany. New York: The American Assembly.

Klein, B., Lerner, A.V., \& Murphy K.M. (2002). Association the economics of copyright 'fair use' in a networked World. The American Economic Review, 92(2). doi:10.1257/000282802320189258. 
Kłoskowska, A. (2011) Kultura masowa. Krytyka i obrona. Warszawa: PWN.

Kuruse, J.F., \& Ross, K.W. (2010). Sieci komputerowe. Ujęcie catościowe. Gliwice: Elion.

Levinson, P. (1999). Digital McLuhan: A Guide to the Information Millennium, London-New York: Routledge. doi:10.4324/9780203164341.

Levinson, P. (2006). Miękkie ostrze, czyli historia i przysztość rewolucji informacyjnej. Warszawa: Musa.

Levinson, P. (2010). Nowe nowe media. Kraków: WAM.

Liebowitz, S.J. (1985). Copying and indirect appropriability: photocopying of journals. The Journal of Political Economy, 93(5). doi:10.1086/261343.

McLuhan, M. (2004). Zrozumieć media. Przedtużenia cztowieka. Warszawa: Wydawnictwa Naukowo-Techniczne.

Moore, G. (1965). Cramming more components onto integrated circuits. Electronics Magazine, 38(8).

Mullin, J. (2011). How 'Cyberlockers' Became The Biggest Problem In Piracy. Retrieved 15.12.2015 from https:/ / gigaom.com.

Price, D. (2013). Sizing the Piracy Universe. London: NetNames.

RapidShare. (2015). Retrieved 15.12.2015 from https: / /www.rapidshare.com.

Richter, F. (2014). Netflix Set to Expand in Europe. Retrieved 15.12.2015 from http://www.statista.com.

Sandvine Inc. (2012). Global Internet Phenomena Report 2H 2012. Retrieved 15.12.2015 from https://www.sandvine.com.

Sandvine Inc. (2014). Global Internet Phenomena Report 2H 2014. Retrieved 15.12.2015 from https://www.sandvine.com.

Sandvine Inc. (2015). Global Internet Phenomena Report 2H 2015. Retrieved 15.12.2015 from https://www.sandvine.com.

Solomon, M. (2011). Fantastic Voyages of the Cinematic Imagination. Georges Méliès's Trip to the Moon. Albany: SUNY Press.

Tassi, P. (2014). ,Game of Thrones' Sets Piracy World Record, But Does HBO Care? Retrieved 15.12.2015 from http://www.forbes.com.

TorrentFreak. (2013). 'Game of Thrones' Most Pirated TV-Show of 2013. Retrieved 15.12.2015 from http://torrentfreak.com.

TorrentFreak. (2013). Game of Thrones Season Finale Sets New Piracy Record. Retrieved 15.12.2015 from http://torrentfreak.com.

TorrentFreak. (2015). Leaked Oscar movie screeners flood torrent sites. Retrieved 15.12.2015 from http://torrentfreak.com.

Ustawa z dnia 4 lutego 1994 r. o prawie autorskim i prawach pokrewnych [Act of 4 February 1994 on copyrights and related rights law] (Dz.U. $1994 \mathrm{nr} 24$ poz. 83) (Poland).

\section{Acknowledgements}

Author contributions: author have given approval to the final version of the article. 


\section{Appendix}

Table 1.

\section{Share of Internet sites in the Internet traffic (first ten) (in \%)}

\begin{tabular}{cccccr}
\multicolumn{2}{c}{ North America* } & \multicolumn{2}{c}{ Europe** $^{* *}$} & \multicolumn{2}{c}{ Asia and Pacific** } \\
Netflix & 34.70 & YouTube & 19.85 & BitTorrent & 31.58 \\
YouTube & 16.88 & HTTP & 16.25 & YouTube & 18.67 \\
HTTP & 6.05 & BitTorrent & 14.40 & HTTP & 8.80 \\
BitTorrent & 4.35 & Facebook & 7.48 & RTSP & 6.29 \\
Amazon Video & 2.94 & SSL & 4.67 & QVoD & 3.20 \\
iTunes & 2.62 & MPEG-others & 3.23 & Facebook & 2.74 \\
Facebook & 2.51 & Netflix & 2.97 & MPEG-others & 2.25 \\
Hulu & 2.48 & Skype & 2.27 & SSL & 1.59 \\
MPEG & 2.16 & RTMP & 2.08 & RTMP & 1.40 \\
SSL-others & 1.99 & Flash Video & 1.74 & Flash Video & 1.39
\end{tabular}

* Data from 2015

** Data from 2014

Source: own preparation based on: Sandvine Inc. (2014, p. 6, 11, 19; 2015, p. 4).

Table 2.

List of movies nominated to the Oscar together with publication date in the BitTorrent network

\begin{tabular}{cccc}
\hline A title & Date of premiere & $\begin{array}{c}\text { Date of publication in Bit- } \\
\text { Torrent network }\end{array}$ & Origin of a copy \\
\hline 'Birdman' & 27.08 .2014 & 07.01 .2015 & Promotional copy \\
'Sniper' & 11.11 .2014 & 07.01 .2015 & Promotional copy \\
'Boyhood' & 19.01 .2014 & 21.11 .2014 & DVD \\
'Grand Budapest Hotel' & 06.02 .2014 & 03.06 .2014 & Web Service \\
'The Imitation Game' & 29.08 .2014 & 07.01 .2015 & Promotional copy \\
'Selma' & 25.12 .2014 & 07.01 .2015 & Promotional copy \\
'Theory of everything' & 07.09 .2014 & 17.01 .2015 & Promotional copy \\
'Whiplash' & 16.01 .2014 & 06.01 .2015 & Promotional copy \\
\hline
\end{tabular}

Source: own preparation. 